\title{
Letter to the Editor: Investigation of Efficacy of Mitomycin-C, Sodium Hyaluronate and Human Amniotic Fluid in Preventing Epidural Fibrosis and Adhesion Using a Rat Laminectomy Model
}

\author{
Elif Bolat ${ }^{1}$, Erdoğan Kocamaz ${ }^{2}$, Zeki Kulahcilar ${ }^{3}$, Ali Yilmaz ${ }^{1}$ \\ Abdullah Topcu ${ }^{4}$, Mevci Ozdemir ${ }^{4}$, Mehmet Erdal Coskun ${ }^{4}$ \\ ${ }^{I}$ Department of Neurosurgery, Dogubeyazit State Hospital, Agri, Turkey \\ ${ }^{2}$ Department of Histology and Embryology, Pamukkale University, School of Medicine, Denizli, Turkey \\ ${ }^{3}$ Department of Neurosurgery, Fatsa Cinar Hospital, Ordu, Turkey \\ ${ }^{4}$ Department of Neurosurgery, Pamukkale University School of Medicine, Denizli, Turkey
}

The article entitled "Investigation of Efficacy of Mitomycin-C, Sodium Hyaluronate and Human Amniotic Fluid in Preventing Epidural Fibrosis and Adhesion Using a Rat Laminectomy Model" published in the Asian Spine Journal highlights an important problem for spinal surgeons [1]. We are thankful to the authors for their comments and informative letter, which highlights the doses which might be helpful in further research. The authors are right because using different dissolving methods can affect the results, but we didn't add any dissolving solution. Regarding the second point about dosage and density, we used a $0.01 \%$ mitomycin C solution [2] (an instant preparation that is usually used for ophthalmologic disorders) and 0.1 $\mathrm{mL}$ sodium hyaluronate [3]. Referring to the last question about the duration time, all of the drugs were applied 3 minutes. We hope those information are helpful and may encourage further research.

\section{Conflict of Interest}

No potential conflict of interest relevant to this article was reported.

\section{References}

1. Bolat E, Kocamaz E, Kulahcilar Z, et al. Investigation of efficacy of mitomycin-C, sodium hyaluronate and human amniotic fluid in preventing epidural fibrosis and adhesion using a rat laminectomy model. Asian Spine J 2013;7:253-9.

2. McEvoy GK. AHFS Drug information 2000: Bethesda, MD: American Society of Health-System Pharmacists; 2000. p.1019-21.

3. Massie JB, Schimizzi AL, Huang B, Kim CW, Garfin SR, Akeson WH. Topical high molecular weight hyaluronan reduces radicular pain post laminectomy in a rat model. Spine J 2005;5:494-502.

Received Jun 13, 2014; Accepted Jun 13, 2014

Corresponding author: Mevci Ozdemir

Department of Neurosurgery, Pamukkale University School of Medicine, 20070, Kinikli, Denizli, Turkey

Tel: +90-258-444-0728, Fax: +90-258-213-4922, E-mail: drmevci@hotmail.com 